\title{
Influence of annealing on X-ray diffraction of natural alexandrite
}

\author{
Rosa Maria Fernandes Scalvi and Lígia de Oliveira Ruggiero \\ Departamento de Física, Faculdade de Ciências-UNESP-C.P. 473, 17033-360-Bauru-SP \\ Máximo Siu Li \\ DFCM-Instituto de Física de São Carlos-USP-C.P. 369, 13560-970-São Carlos-SP
}

(Received 11 March 2001; accepted 25 October 2001)

\begin{abstract}
In this work we present results of X-ray diffraction using powder method, on natural alexandrite samples from Minas Gerais State (Brazil), as a function of a sequence of annealing. From these measurements we determine lattice parameters before ( $a=9.405 \AA, b=5.471 \AA, c=4.409 \AA)$ and after annealing, and its structure is confirmed as orthorhombic. Measurements done after an annealing of 15 minutes at $700{ }^{\circ} \mathrm{C}$ and for 5 hours at $1000^{\circ} \mathrm{C}$ indicate the migration of atoms present in the sample through different phases, which were also identified by Microprobe Analysis (WDS). However we have verified that such migration does not modify the structure. X-ray diffraction measurements have been carried out in conjunction with optical absorption in the UV-Vis as a function of annealing. (C) 2002 International Centre for Diffraction Data.
\end{abstract}

[DOI: $10.1154 / 1.1428284$ ]

Key words: alexandrite, optical absorption, X-ray diffraction

\section{INTRODUCTION}

Alexandrite is how the $\mathrm{Cr}$ doped chrysoberyl $\left(\mathrm{Be}_{2} \mathrm{Al}_{2} \mathrm{O}_{4}\right)$ is usually known. This material belongs to orthorhombic crystal system and Pnma space group. Its structure was first determined in 1926 by Bragg and Brown and refined in 1963 by Farrel and co-workers (Farrel et al., 1963). Chrysoberyl has a hexagonal close packed structure (hcp) of oxygen ions slightly distorted with $\mathrm{Al}^{3+}$ and $\mathrm{Be}^{2+}$ occupying octahedral and tetrahedral sites, respectively (Rabadanov and Dudka, 1997). Distortions from a perfect hcp structure of oxygen ions, which is shifted from the $c$ axis, yields two octahedrally coordinated sites: $\mathrm{Al}_{1}$ located at an inversion plane and $\mathrm{Al}_{2}$ located at reflection plane. Figure 1 shows a three-dimension chrysoberyl structure.

Interatomic distances in the chrysoberyl structure have been determined by Farrel and co-workers (Farrel et al., $1963)$ and the average distances between nearest neighbors are (considering $\mathrm{O}_{1}, \mathrm{O}_{2}$ and $\left.\mathrm{O}_{3}\right): \mathrm{Al}_{1}-\mathrm{O}=1.890 \AA\left(C_{i}\right.$ symmetry) and $\mathrm{Al}_{2}-\mathrm{O}=1.934 \AA$ ( $C_{s}$ symmetry) (Schmetzer et al., 1980; Forbes, 1983; Hassan and El-Rakhawy, 1974). Table I presents equivalent position coordinates in the chrysoberyl structure (Phakey, 1969).

It is well known that the larger site is preferentially occupied by $\mathrm{Cr}^{3+}$ ions and it is the main responsible by alexandrite optical properties (Powell et al., 1985). However, the exact distributions of $\mathrm{Cr}^{3+}$ ions in $\mathrm{Al}_{1}$ and $\mathrm{Al}_{2}$ sites is not quite known and several techniques have been employed to study this material, such as optical absorption and emission, electronic paramagnetic resonance (EPR), and nuclear magnetic resonance (NMR) (Forbes, 1983; Yeom et al., 1997; Jovanic, 1996).

Mineral (or phase) characterization can also be done with the help of X-ray diffraction. In this case the spacing between phases ( $d$ values) are physical characteristics of a material as well as the density or refraction index. Due to the difficulty of finding natural crystals with a well-defined arrangement of atoms, such as alexandrite, X-ray diffraction measurements using powder method is more indicated than methods where a precise orientation is needed, as the Laue method, for example.

In this work, our main goal is to verify the effect of a sequence of annealing on the structural properties of natural alexandrite, which present other impurities, besides $\mathrm{Fe}$ and $\mathrm{Cr}$.

\section{EXPERIMENTAL}

$\mathrm{X}$-ray diffraction measurements were carried out in a D500 Siemens diffractometer, operating with a $K_{\alpha}$ line from $\mathrm{Cu}$ emission and wavelength of $1.5406 \AA$. Angle $(2 \theta)$ range goes from 5 degrees to 80 degrees and it used a divergence slit and antiscattering slit of $3^{\circ}$, step of $0.033^{\circ}$. The exposition time is $1 \mathrm{~s}$, and used a spinning sample holder with 120 rpm. It also used a secondary graphite monochromator.

Optical absorption was done with a Cary 17 spectrophotometer in the range $185 \mathrm{~nm}$ to $700 \mathrm{~nm}$, at room temperature. Optical absorption allows to study material optical properties, which are influenced by the presence of impurities in the

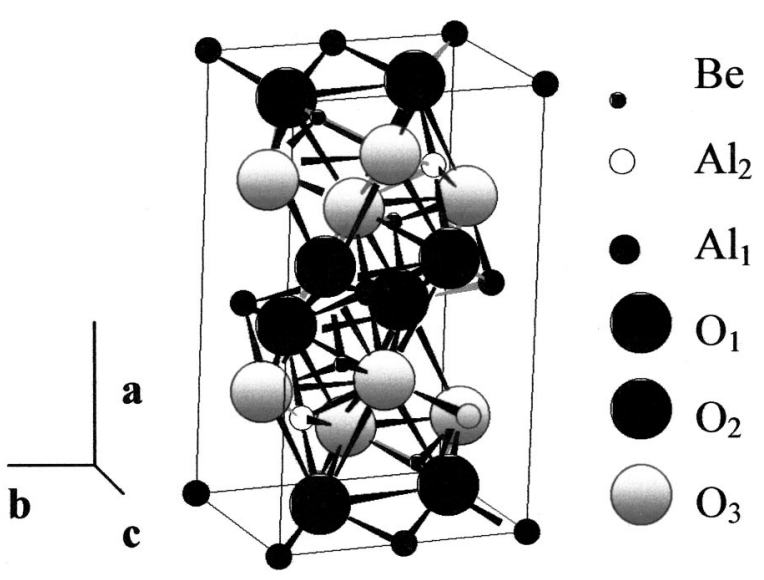

Figure 1. Chrysoberyl structure with indication of $a, b$, and $c$ axis. 
TABLE I. Positions occupied by atoms in the chrysoberyl structure (Phakey, 1969).

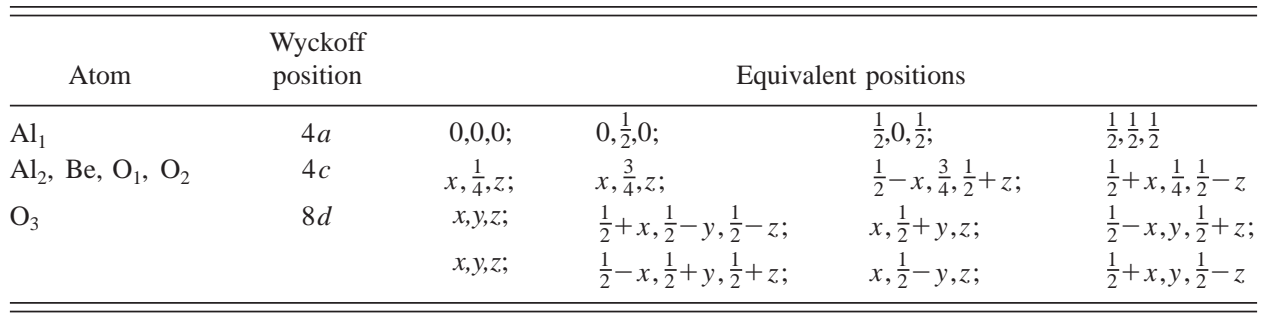

host matrix, since occasional thermal processes can modify some material characteristics, such as aggregate formation, diffusion processes or desegregation. We used optical absorption in the UV-VIS in conjunction with X-ray diffraction.

Natural alexandrite samples used to X-ray diffraction measurements, AN1 (before the annealing), AN2 (after the 15 minutes annealing at $700{ }^{\circ} \mathrm{C}$, called here TT1) and AN3 (after 5 hours of annealing at $1000{ }^{\circ} \mathrm{C}=\mathrm{TT} 2$ ), come from only one piece cut in three similar parts and were ground separately and left with a very fine granulation (325 mesh). To the obtained powder was added isopropyl alcohol and deposited on glass plates, in order to do the analysis. Annealing were done in a muffle oven model CON3P-1800 of EDG, at $1 \mathrm{~atm}$ (regular atmospheric pressure), varying the annealing time and temperature. The decrease of temperature was done immediately after the temperature reaches the preferred plateau of high temperature. Then the sample is removed from the over and left in air over a glass plate at room temperature. Then the temperature decreases quickly, avoiding formation of agglomerates of other impurities, which could occur back, since they were dissociated by the annealing. Optical absorption was done on a sample (AN4) obtained from another stone and cut on a platelike shape $1.17 \mathrm{~nm}$ thick. The same annealing used for the samples used to $\mathrm{X}$-ray measurements was done in the AN4 sample.

\section{RESULTS AND DISCUSSION}

Figure 2(a) shows X-ray diffraction results obtained from AN1, with normalized intensity. Besides the chrysoberyl structure, it has also identified the presence of two other structures: quartz and mica, which were detected by microprobe analysis (WDX). Figures 2(b) and 2(c) show X-ray diffraction results for samples AN2 (after TT1) and AN3 (after TT2), also with normalized intensity values.

From X-ray diffraction obtained on sample AN1 (without annealing) and using a program called DICVOL91, the following lattice parameters were obtained: $a=9.405 \AA, b$ $=5.471 \AA$, and $c=4.409 \AA$. These values are in very good agreement with results published elsewhere (JCPDS, 1998). With X-ray diffraction results it was also verified that distances between planes $(d)$ agree totally with results obtained from natural alexandrite from Minaçu, State of Goiás, Brazil (Petersen, 1998). However, some discrepancies have been found on relative intensities of some lines of the spectra. These differences can be attributed to several factors such as different concentration of impurities in the matrix of natural alexandrite, different orientation in the sample, and experimental variations.
After TT1 the lattice parameters have a slight increase, about $1 \%$, and $\mathrm{X}$-ray shows a preferential orientation in the (620) direction. In this case we have $a=9.417 \AA, b$ $=5.491 \AA$, and $c=4.226 \AA$. After the TT2 lattice parameters go back to closer values to those previously measured before the annealing, since the X-ray spectra show diffraction lines with relative intensities very similar to those obtained before annealing. In this case $a=9.409 \AA, b=5.483 \AA$, and $c$ $=4.432 \AA$.

Concerning X-ray diffraction spectra it is also possible to notice a slight line shift towards lower values of $2 \theta$ after
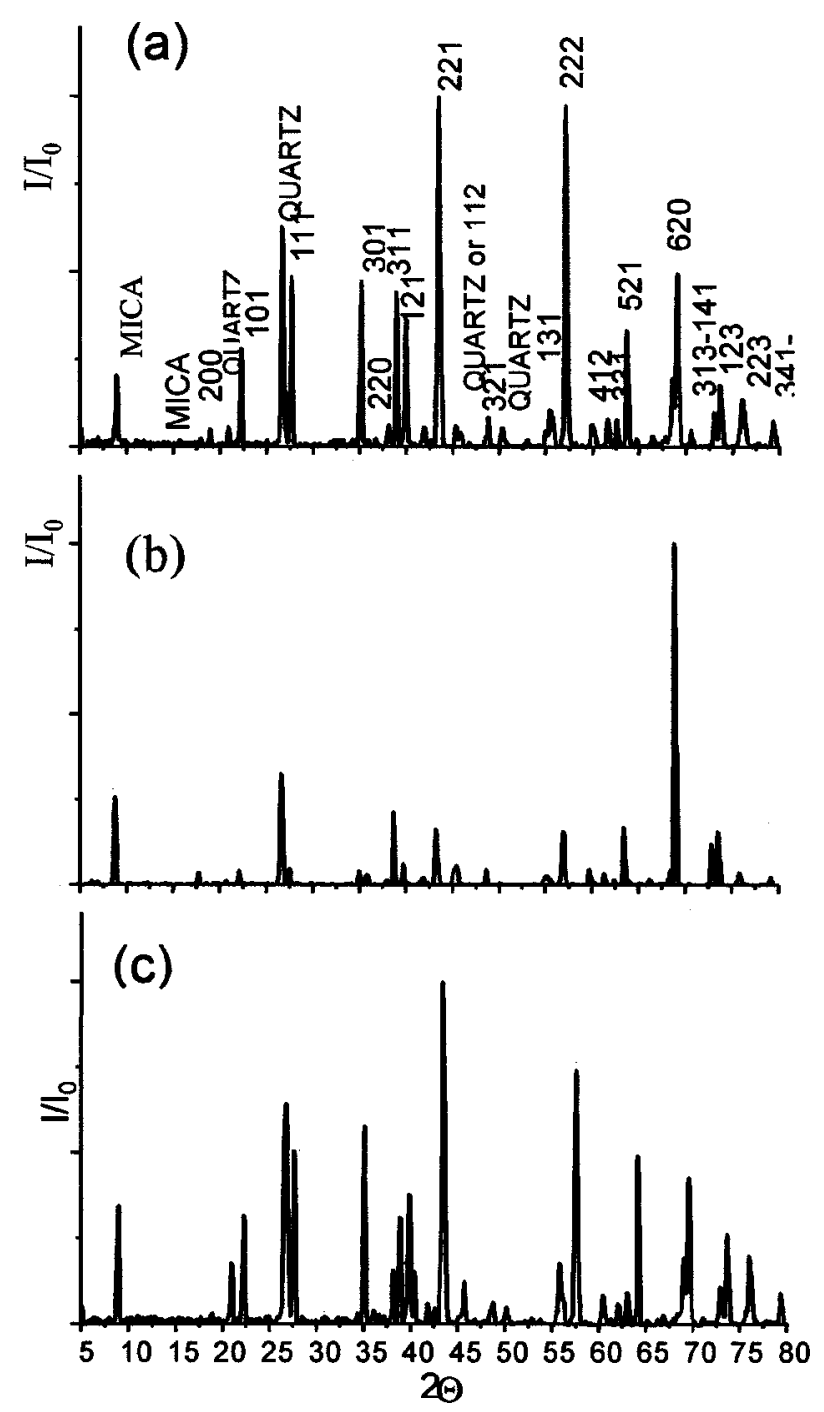

Figure 2. X-ray diffraction spectra for natural alexandrite. (a) Natural sample AN1, before annealing; (b) natural sample after TT $1=700^{\circ} \mathrm{C}$ for 15 minutes; (c) natural sample after TT $2=1000^{\circ} \mathrm{C}$ for 5 hours. 


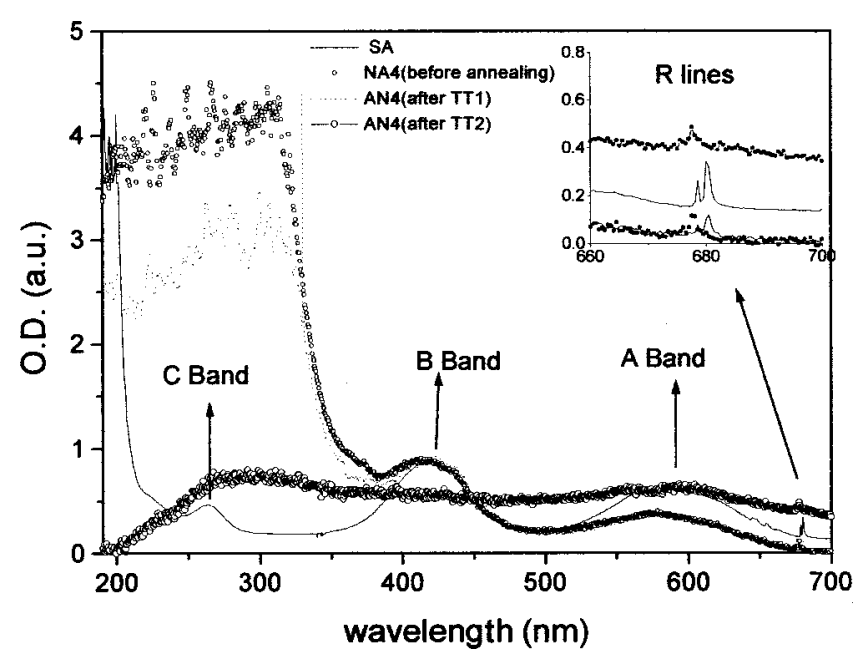

Figure 3. Optical absorption in the UV-Vis to synthetic and natural alexandrite before and after annealing TT1 $\left(700{ }^{\circ} \mathrm{C}\right.$ for 15 minutes) and TT2 $\left(1000^{\circ} \mathrm{C}\right.$ for 5 hours).

TT1, and another diffraction line shift after TT2, practically back to the position before annealing. Although small, lattice parameter variation can be interpreted as a change in the local chemical composition of each phase present in this sample, which means the substitution of some atoms from the lattice by others with slightly different dimensions. As a result, there is a small modification on cell dimensions and consequently we observe a shift position on lines of X-ray spectra, corresponding to spacing between crystalline planes. These results may indicate migration of atoms present in the sample, through different phases, as identified by microprobe analysis (WDX), such as quartz and mica, besides alexandrite.

Alexandrite optical absorption has been extensively presented in the literature from $4 \mathrm{~K}$ to $300 \mathrm{~K}$ (Powell et al., 1985; Liu et al., 1995; Walling et al., 1985; Zhang et al., 1993). These spectra show two narrow lines close to $680 \mathrm{~nm}$, called $R$ lines, which are identified as $\mathrm{Cr}^{3+}$ lines, associated with ions at sites located on a reflection plane $\left(\mathrm{Al}_{2}\right.$ sites). Spectra also present two broad bands about $580 \mathrm{~nm}$ and 420 $\mathrm{nm}$ associated with transitions from the fundamental state ${ }^{4} A_{2}$ to excited states ${ }^{4} T_{2}$ and ${ }^{4} T_{1}, A$ band and $B$ band, respectively. Figure 3 presents optical absorption spectra of sample AN4 before and after being submitted to annealing TT1 and TT2. Figure 3 also shows an optical absorption spectra of synthetic alexandrite (AS), which has only $\mathrm{Cr}^{3+}$ impurity, for comparison with the natural alexandrite. By WDX measurements we determine partial concentration of impurities present in the natural sample 0.13 at. $\%$ of $\mathrm{Fe}$ and 0.073 at. $\%$ of $\mathrm{Cr}$.

$A$ and $B$ bands are attributed to first and second spin allowed electronic transitions in the partially filled $3 d$ shell of $\mathrm{Cr}^{3+}$ ion. The first spin allowed transition $\left(v_{1}\right)$ is exactly $\Delta(=10 \mathrm{Dq}) \quad$ (Underhill, 1966). Then, for the synthetic sample $\mathrm{Dq}=1734 \mathrm{~cm}^{-1}$ to $\mathrm{Cr}^{3+}$ surrounded by six oxygen atoms, and for natural samples Dq is between $1754 \mathrm{~cm}^{-1}$ and $1705 \mathrm{~cm}^{-1}$. The work of Hassan and El-Rakhawy (1974), concerns synthetic alexandrite, a third spin allowed transition $\left(v_{3}\right)$ can be expected and calculated by $340 \mathrm{Dq}^{2}-18\left(v_{2}\right.$ $\left.+v_{3}\right) \mathrm{Dq}+v_{2} v_{3}=0$ (Underhill, 1966). In Figure 3 it can be observed that only in the case of the synthetic sample, which does not contain Fe, there is a UV band around $265 \mathrm{~nm}$, whereas for natural alexandrite, with higher Fe concentration (0.13 at. \%) than $\mathrm{Cr}(0.073$ at. \%), the UV band attributed to $\mathrm{Cr}^{3+}$ cannot be observed. Natural sample presents quartz and mica inclusions and visible optical absorption is rather intense. However, we must take into account that the sharp increase in the higher energy side of band $B$ of natural alexandrite is due to light dispersion effect in this region, since this sample is rather opaque and irregular, compared to the synthetic sample. Table II shows the calculated half-width, intensity (absorption coefficient), and position of absorption bands to synthetic and natural alexandrite before and after annealing.

From Table II we notice that the $A$ band has its average central position slightly modified by first annealing (TT1) and a quite observable modification occurs to this band after 5 hours annealing (TT2), when the $A$ band position is shifted about $16.5 \mathrm{~nm}$ towards lower energy direction, related to its position before annealing. Intensity of this band has a strong decrease with TT2. However, we observe that it is hard to define a central position of $A$ band, since its half-width is significantly increased with TT2. These results indicate that annealing affects the relative position of $\mathrm{Cr}^{+3}$ ions located at different sites, mainly in the case of 5 hour annealing.

TABLE II. Results of optical absorption in the UV-Vis, at room temperature. $\lambda$ indicates maximum positions, $\alpha$ is the absorption coefficient and $e \Delta \lambda$ is the half-width of the absorption band.

\begin{tabular}{|c|c|c|c|c|c|c|c|}
\hline \multirow[b]{2}{*}{ Sample } & \multicolumn{3}{|c|}{$A$ band $\left(\mathrm{Cr}^{3+}\right)$} & \multicolumn{3}{|c|}{$B$ band $\left(\mathrm{Cr}^{3+}, \mathrm{Fe}^{3+}\right)$} & \multirow{2}{*}{$\frac{R \text { lines }}{\lambda(\mathrm{nm})}$} \\
\hline & $\lambda(\mathrm{nm})$ & $\alpha\left(\mathrm{cm}^{-1}\right)$ & $\Delta \lambda(\mathrm{nm})$ & $\lambda(\mathrm{nm})$ & $\alpha\left(\mathrm{cm}^{-1}\right)$ & $\Delta \lambda(\mathrm{nm})$ & \\
\hline AS & 576.5 & 3.55 & 99.50 & 424.5 & 8.54 & 62.50 & $\begin{array}{l}678.5 \\
680.5\end{array}$ \\
\hline $\begin{array}{l}\text { AN4 } \\
\text { (before } \\
\text { annealing) }\end{array}$ & 576.5 & 6.12 & 98.39 & 418.0 & 7.39 & 51.61 & $\begin{array}{l}678.0 \\
679.5\end{array}$ \\
\hline $\begin{array}{l}\text { AN4 } \\
\text { (after TT1) }\end{array}$ & 577 & 6.06 & 98.14 & 415 & 7.80 & 53.70 & 677.5 \\
\hline $\begin{array}{l}\text { AN4 } \\
\text { (after TT2) }\end{array}$ & 593 & 4.79 & 130.10 & & & & 677.5 \\
\hline
\end{tabular}


The $B$ band, which is related to the presence of $\mathrm{Cr}^{3+}$ and $\mathrm{Fe}^{3+}$ impurities in the chrysoberyl structure, has its position slightly shifted to lower energy direction after TT1. After TT2 it is no longer possible to observe this band clearly. The $B$ band also has significant alteration in its intensity and width. A possible explanation for the $B$ band behavior is that there is relative variation of $\mathrm{Cr}^{3+} / \mathrm{Fe}^{3+}$ concentration in $\mathrm{Al}_{1}$ and $\mathrm{Al}_{2}$ sites with annealing. Then ions migrate to other sites of the host matrix.

$\mathrm{Cr}^{3+}$ lines of sites located on a reflection plane also seem to have some alteration in its behavior after annealing, since they become difficult to be distinguished from each other. Actually they now look like a single broad band around $677.5 \mathrm{~nm}$.

Then, annealing seems to influence much more the band attributed to $\mathrm{Cr}^{3+}$ and $\mathrm{Fe}^{3+}$ impurities ( $B$ band) than the band attributed to $\mathrm{Cr}^{3+}$ impurity ion on both sites of the alexandrite ( $A$ band).

\section{CONCLUSION}

Solid inclusions have been detected in natural alexandrite by microprobe analysis (WDX), such as quartz and mica. Other impurities besides $\mathrm{Cr}^{3+}$ and $\mathrm{Fe}^{3+}$ have also been identified, such as $\mathrm{Mg}$, Ti, $\mathrm{Si}, \mathrm{Ca}$, and $\mathrm{K}$. These measurements also help to verify that Fe concentration in the natural sample is much higher than $\mathrm{Cr}$ concentration. The presence of other impurities and the formation of solid inclusions in natural samples have been confirmed with X-ray diffraction measurements, which allow to determine lattice parameters and the orthorhombic crystalline structure. Annealing does not alter alexandrite structure, as we figure out X-ray diffraction and optical absorption measurements.

\section{ACKNOWLEDGMENTS}

The authors would like to thank Professor Luis V. A. Scalvi for fruitful discussions. We also thank financial agencies: FAPESP, CAPES, FUNDUNESP, and PRONEX.

Farrel, E. F., Fang, J. H., and Newham, R. E. (1963). "Refinement of the chrysoberyl structure," Am. Mineral. 48, 804-810.

Forbes, C. E. (1983). "Analysis of the spin Hamiltonian parameters for $\mathrm{Cr}^{3+}$ in mirror and inversion symmetry sites of alexandrite $\left(\mathrm{Al}_{2-x} \mathrm{Cr}_{x} \mathrm{BeO}_{4}\right)$. Determination of the relative site occupancy by EPR," J. Chem. Phys. 79, 2590-2599.

Hassan, F., and El-Rakhawy, A. (1974). "Chromium III centers in synthetic alexandrite," Am. Mineral. 59, 159-165.

JCPDS-International Centre for Diffraction Data (1998). 81-1049.

Jovanic, B. R. (1996). "High pressure on the R1 line lifetime in alexandrite $\mathrm{BeAl}_{2} \mathrm{O}_{4}: \mathrm{Cr}^{3+}$," J. Lumin. 68, 43-48.

Liu, Y. et al. (1995). "Relationship between the crystallographic orientation and the effect alexandrite in synthetic alexandrite," Miner. Mag. 59, $111-114$.

Petersen, Jr., K. J. (1998). Thesis, Instituto de Geociências, USP-São Paulo.

Phakey, P. P. (1969). "Transmission electron microscope study of anti-phase boundaries in alexandrite $\left(\mathrm{Al}_{2-x} \mathrm{Cr}_{x} \mathrm{BeO}_{4}\right)$," Phys. Status Solidi 32, 801-814.

Powell, R. C. et al. (1985). "Spectroscopic properties of alexandrite crystals," Phys. Rev. B 32, 2788-2797.

Rabadanov, M. K., and Dudka, A. P. (1997). "Comparative structural study of $\mathrm{Al}_{2} \mathrm{BeO}_{4}$ and $\mathrm{Al}_{2} \mathrm{BeO}_{4}: \mathrm{Cr}^{3+}\left({ }^{\circ} 3\right.$ at\% $\left.\mathrm{Cr}\right)$ crystals," Inorg. Mater. (Transl. of Neorg. Mater.) 33, 48-51.

Schmetzer, K., Bank, H., and Gubelin, E. (1980). "The alexandrite effect in minerals: Chrysoberyl, Garnet, Corundum, Fluorite,” N. Jb. Miner. Abh. 138, 147-164.

Underhill, A. E. (1966). "Calculation of the Racah parameter B for Nickel (II) and Cobalt (II) compounds," Nature (London) 210, 834-835.

Walling, J. C. et al. (1985). "Tunable alexandrite lasers: Development and performance," IEEE J. Quantum Electron. QE-21, 1568-1581.

Yeom, T. H. et al. (1997). "Spin lattice relaxations of ${ }^{9} \mathrm{Be}$ and ${ }^{27} \mathrm{Al}$ single crystalline alexandrite," J. Appl. Phys. 82, 2472-2475.

Zhang, Z. et al. (1993). "Thermal characteristics of alexandrite fluorescence decay at high temperatures, induced by a visible laser diode emission," J. Appl. Phys. 73, 3493-3498. 